\title{
Performance Analysis and Comparison of a Concentrated Photovoltaic System with Different Phase Change Materials
}

\author{
Jawad Sarwar ${ }^{1}$, Muhammad Rizwan Shad ${ }^{2}$, Arshmah Hasnain ${ }^{1}$, Farman Ali ${ }^{1}$, Konstantinos E. Kakosimos ${ }^{3,4} \mathbb{D}$ \\ and Aritra Ghosh $5, *$ (D)
}

check for

updates

Citation: Sarwar, J.; Shad, M.R.; Hasnain, A.; Ali, F.; Kakosimos, K.E.; Ghosh, A. Performance Analysis and Comparison of a Concentrated Photovoltaic System with Different Phase Change Materials. Energies 2021, 14, 2911. https://doi.org/ $10.3390 /$ en14102911

Academic Editor:

Alessandro Cannavale

Received: 16 March 2021

Accepted: 12 May 2021

Published: 18 May 2021

Publisher's Note: MDPI stays neutral with regard to jurisdictional claims in published maps and institutional affiliations.

Copyright: (c) 2021 by the authors. Licensee MDPI, Basel, Switzerland. This article is an open access article distributed under the terms and conditions of the Creative Commons Attribution (CC BY) license (https:/ / creativecommons.org/licenses/by/ $4.0 /)$.
1 Department of Mechanical Engineering, University of Engineering \& Technology, Lahore 54000, Pakistan; jawad.sarwar@uet.edu.pk (J.S.); 2016me128@student.uet.edu.pk (A.H.); farmanali.uet21@gmail.com (F.A.)

2 Department of Mechanical Engineering, University of Central Punjab, Lahore 54782, Pakistan; dr.rizwan@ucp.edu.pk

3 Chemical Engineering Department, Texas A\&M University at Qatar, P.O. Box 23874, Doha, Qatar; k.kakosimos@qatar.tamu.edu

4 Aerosol \& Particle Technology Laboratory, Chemical Process \& Energy Resources Institute, Centre for Research \& Technology Hellas (APTL/CPERI/CERTH), P.O. Box 60361, GR 57001 Thermi, Thessaloniki, Greece

5 College of Engineering, Mathematics and Physical Sciences, Renewable Energy, University of Exeter, Penryn, Cornwall TR10 9FE, UK

* Correspondence: a.ghosh@exeter.ac.uk
Abstract: In this work, temperature regulation and electrical output of a concentrated photovoltaic system coupled with a phase change material (CPVPCM) system is investigated and compared with a single sun crystalline photovoltaic (PV) system. A fully coupled thermal-optical-electrical model has been developed in-house to conduct the simulation studies for actual weather conditions of Doha (Qatar) and selected phase change materials (PCMs). The selected PCMs are lauric acid, RT47, S-series salt, STL47, ClimSel ${ }^{\mathrm{TM}}$ C48, RT54, RT60, RT62, and RT64. An optical concentration ratio of $20 \times$ is considered on a $15 \mathrm{~mm}$ wide crystalline silicon cell. The temperature evolution, thermal energy storage and electrical output of the CPVPCM system are obtained for 48-hour simulations with representative weather conditions for each month of a typical meteorological year (TMY). Results and overall thermal and electrical efficiency are compared for each PCM. In brief, the CPVPCM system with S-series salt performs better than all other PCM with an overall efficiency of $54.4 \%$. Furthermore, this system consistently produces more power than a PV system with an equal footprint $\left(1 \mathrm{~m}^{2}\right)$ for each month of the TMY.

Keywords: concentrated photovoltaic; finite element method; overall efficiency; phase change material; thermal efficiency

\section{Introduction}

Concentrator photovoltaic (CPV) systems focus sunlight onto a photovoltaic (PV) cell where it is concomitantly converted into electricity and heat [1]. The concentration of the sunlight increases the temperature of the PV cell. Therefore, cooling of such a system is essential [2] as an elevated PV cell temperature leads to a decreased electrical energy output [3]. Many schemes exist for cooling, usually classified as passive or active cooling [4]. Among passive cooling schemes, application of a phase change material (PCM) is an attractive option due to their ability to maintain a nearly constant temperature close to the melting temperature [5]. Furthermore, PCMs can also absorb a significant amount of energy, mainly as latent heat during the phase transformation, which provides an added advantage of allowing the storage and use of heat to be run asynchronously [6].

In the past, experimental and numerical studies have demonstrated that the incorporation of a PCM behind a PV increases the yearly electrical power output by $5.9 \%$ as compared to a PV system, e.g., in [5]. A transient 1-D heat transfer model was investigated 
by [7]. Three different PCM materials, including RT20, RT25 and RT28HC, were used to evaluate the effects of the PCM melting point. A maximum 5\% increase in efficiency was achieved for a PVPCM system as compared to a flat plate system. A thermal energy model of PV, integrated with enthalpy model of PCM was proposed and tested for a layer of PCM with a melting point of $44^{\circ} \mathrm{C}$ and $20 \mathrm{~mm}$ thickness [8]. The maximum reduction in average and the peak temperatures was found to be $13 \%$ and $33 \%$ with PCM. An improvement of $15.3 \%$ in the average efficiency and $17.6 \%$ in the minimum efficiency values was observed by adding PCM to a conventional PV module. An indoor experimental study has shown an electrical efficiency improvement of $7.7 \%$ for a building-integrated CPVPCM system (geometrical concentration ratio of 2.7 ) compared to a naturally ventilated CPV system [9]. In a theoretical study conducted for the environmental conditions of Doha (Qatar), a CPVPCM system (concentration ratio of 25) was able to produce power in the range of $-4.7 \%$ to $21.7 \%$ as compared to a flat plate system while keeping the temperature of the system below $85^{\circ} \mathrm{C}$ year round [10]. A 2D thermal model for an embedded CPV with a coupled thermo-fluids model for investigating the phase change phenomenon of PCM was presented in [11]. The system was evaluated at three $\mathrm{CR}(\mathrm{s})$ of 5,10 and 20 with $\mathrm{CaCl}_{2} \cdot 6 \mathrm{H}_{2} \mathrm{O}$ as PCM. In order to determine the effect of the PCM height on the thermal and flow behavior, three PCM thicknesses of 50, 100 and $200 \mathrm{~mm}$ were considered. It was found that temperature of $\mathrm{PV}$ module was reduced from 510 to $64{ }^{\circ} \mathrm{C}$ for $2 \mathrm{~h}$ for CPV/PCM system with CR of 20 and $200 \mathrm{~mm}$ thick PCM. It was concluded that PCM is effective in temperature reduction of CPV / PCM system at higher concentration ratios. A 2-D heat transfer incorporating enthalpy based formulation is presented in [12]. Different PCMs (paraffin, salt hydrate and fatty acids) were examined to determine the optimum PCM type with the optimum container configuration. Salt hydrate was found to be the optimum type of PCM as it offers the same cooling performance with a small amount of material. The results also indicated a total energy efficiency of $60 \%$ with PCM in the CPV configuration and $30 \%$ for only CPV configuration. The integration of a PCM also alleviates the temperature fluctuations in a concentrating photovoltaic-thermoelectric system [13]. At the same time, the ambient temperature and thermo physical properties of the PCM effect the electrical output of the CPVPCM system. A comparison on the thermal and electrical output of a CPVPCM system with different phase change materials is presented in [14] for the environmental conditions of Lahore (Pakistan). Out of nine commercially available PCMs, S-series salt was found to be the best for the analyzed configuration and the environmental conditions due to its higher overall efficiency. The effect of PCM melting temperature on the performance was also analyzed by [8]. It was inferred that system performance is optimum for a temperature difference of $10-12{ }^{\circ} \mathrm{C}$ between the PCM melting point and the average minimum ambient temperature of the hottest month. This optimum performance is due to the maximum utilization of the heat storage capacity of PCM. It is reported that the ambient conditions alone can reduce electrical output by 10\% [1]. When PCM thermo-physical properties are not properly selected. Previously a PV system was investigated in an Indian location which offered a promising outcome [15-18]. Clearly, selection of the PCM depends on the weather conditions and for the selected study, the area of Doha, Qatar with a tropical dry climate a CPVPCM system should be equipped with a PCM with melting temperature between $45^{\circ} \mathrm{C}$ to $65^{\circ} \mathrm{C}$.

Quantification of the exact properties and performance of the CPVPCM demands for numerical modeling the optical, thermal and electrical behavior of such a system. In this work, an updated electrical model, which includes the effect of concentrated irradiance on the series resistance, is coupled with a previously developed thermal and optical model for a CPVPCM system. The developed coupled thermal-optical-electrical model is used to predict and compare the electrical power and temperatures of a CPVPCM and PV (without PCM) systems over two consecutive days per month of a typical meteorological year for Doha (Qatar); a location with a tropical dry climate. 


\section{Methodology}

\subsection{Physical Model}

A schematic illustration of the studied CPVPCM and its main components is shown in Figure 1. A parabolic trough concentrator focuses the incoming sunlight onto the PV cell with $10 \mathrm{~mm}$ width and solar to electrical conversion efficiency of $>16 \%$ [19]. The rear side of cell is attached to an aluminum container with the PCM, and the front side to a Sylgard ${ }^{\circledR}$ 184 silicone elastomer (Dow, USA) of $0.6 \mathrm{~mm}$ thickness.

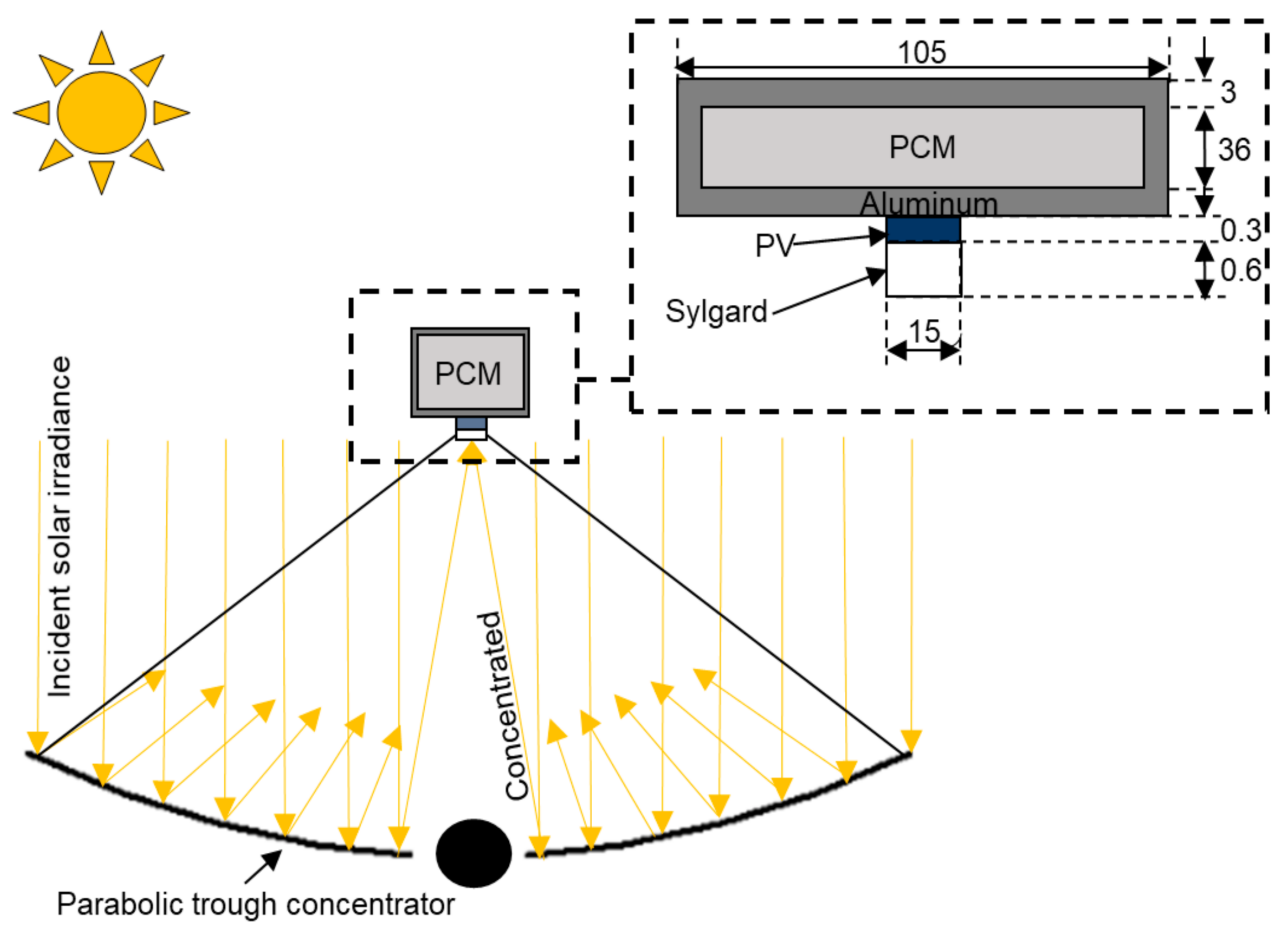

Figure 1. Physical schematic of CPVPCM system (not to scale).

The parabolic trough concentrator is considered non-ideal with an optical concentration ratio of $20 \times$, to achieve a uniform flux distribution and minimal spillage losses. The inclination angle of the PV system is $\sim 25.3^{\circ}$ with a true south orientation while the CPVPCM system has a single axis tracking. Typical selection criteria for PCM suitability are the phase transformation temperature, the latent heat of fusion, the thermal conductivity, and the reversibility of the phase transformation. Based on these, nine commercially available PCM have been selected having phase transformation temperature between $\sim 45-65{ }^{\circ} \mathrm{C}$. Their thermo-physical properties are presented in Table 1 where $T_{m}$ represents melting temperature, $\mathrm{H}$ is the latent heat of fusion, $\mathrm{k}$ is the thermal conductivity, $\rho$ represents the density and $c_{p}$ represents specific heat capacity.

\subsection{Irradiance and Weather Condition}

The clear sky broadband solar radiation model [20] is used to acquire the direct beam irradiance and global horizontal irradiance for the CPVPCM system and the PV system respectively. Both systems are assumed to be installed at Education city, Doha, Qatar having a latitude and longitude of $25.314779^{\circ} \mathrm{N}$ and $51.43978^{\circ} \mathrm{E}$ respectively. The representative 48-hour weather data (wind speed and ambient temperature) for each month is obtained from the Qatar Meteorological Department as shown in Figure 2. This data serves as an input to the developed model presented in Section 2.4. 
Table 1. Thermo physical properties of the phase change materials, Aluminum, photovoltaic and Sylgard ${ }^{\circledR}$.

\begin{tabular}{cccccccc}
\hline & & $\mathbf{T}_{\mathbf{m}}$ & & $\mathbf{H}$ & $\mathbf{k}$ & $\boldsymbol{\rho}$ & \multicolumn{2}{c}{$\mathbf{c}_{\mathbf{p}}$} \\
\hline & & ${ }^{\circ} \mathbf{C}$ & & $\mathbf{k J} / \mathbf{k g}$ & $\mathbf{W} / \mathbf{m K}$ & $\mathbf{k g} / \mathbf{m}^{\mathbf{3}}$ & \multicolumn{2}{c}{$\mathbf{k J} \mathbf{k g K}$} \\
\hline On & & End & & & & $\mathbf{s}$ & $\mathbf{l}$ \\
\hline La & 42 & 44 & 178 & 0.15 & 1007 & 2 & 2 \\
RT47 & 41 & 48 & 165 & 0.20 & 880 & 2 & 2 \\
S-SERIES SALT & 45 & 47 & 220 & 0.60 & 1450 & 2 & 2 \\
STL47 & 47 & 49 & 221 & 1.34 & 1350 & 2 & 2 \\
C48 & 48 & 53 & 180 & 0.76 & 1300 & 2 & 2 \\
RT54 & 53 & 54 & 200 & 0.20 & 850 & 2 & 2 \\
RT60 & 55 & 61 & 160 & 0.20 & 880 & 2 & 2 \\
RT62 & 62 & 63 & 230 & 0.20 & 850 & 2 & 2 \\
RT64 & 63 & 65 & 250 & 0.20 & 880 & 2 & 2 \\
Aluminium & $\times$ & $\times$ & $\times$ & 211 & 2675 & 0.9 & $\times$ \\
PV & $\times$ & $\times$ & $\times$ & 125.4 & 2205 & 0.8 & $\times$ \\
SYLGARD & $\times$ & $\times$ & $\times$ & 0.27 & 1030 & 1.1 & $\times$ \\
PERSPEX & $\times$ & $\times$ & $\times$ & 1.9 & 1190 & 1.3 & $\times$ \\
\hline
\end{tabular}
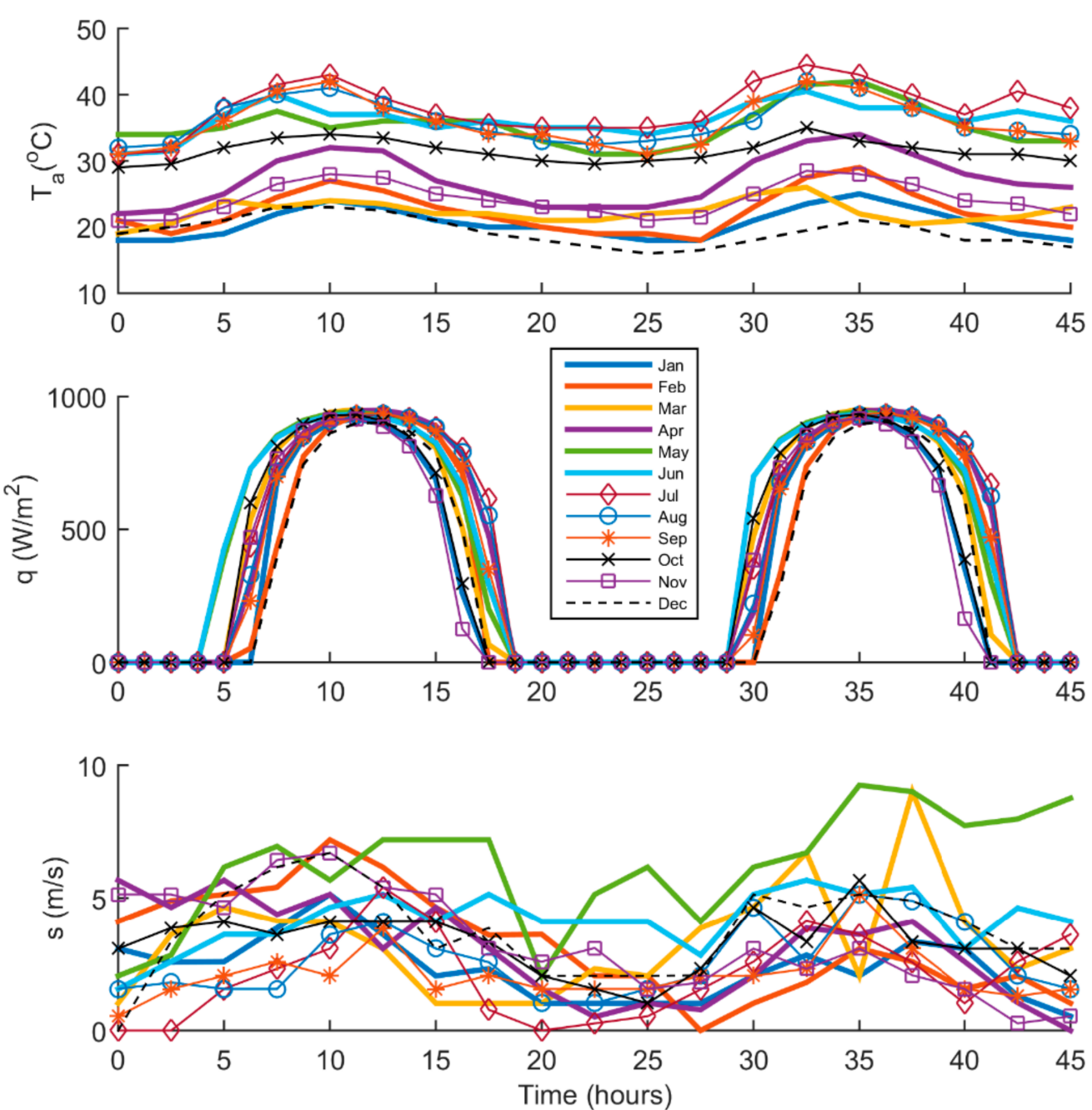

Figure 2. Irradiance, wind speed and ambient temperature for selected days of the year. 


\subsection{Optical Design of the Non-Ideal Solar Concentrator for Photovoltaic Application}

A non-ideal parabolic trough concentrator is used in the presented work. A parabolic trough consists of reflector mirrors that concentrate the coming sunlight onto the focal point of the parabola [21]. An ideal parabolic concentrator focuses sunlight on to a point but creates non-uniform spatial flux distribution at the focal point. This spatial non-uniform flux distribution effects the efficiency of the PV cell by reducing fill factor and short circuit current density [22]. Furthermore, due to non-uniform flux, the electron flow will be confined within the cell, which causes the electron sink, or a hot spot that can damage the PV. Therefore, it is important to achieve uniform flux at the PV to achieve maximum solar to electrical conversion efficiency. In the present work non-ideal, a parabolic concentrator is designed according to the given methodology in [23]. Having a concentration ratio of $20 \times$, a non-ideal concentrator consists of various flat $15 \mathrm{~mm}$ equal segments whose incident and reflection angle is the same; which reflect the same portion of incident light onto the receiver. The design parabolic concentrator is shown in Figure 7.

The effective concentration ratio of the concentrator is defined as the area of flux received at the $\mathrm{CPV}$ to the flux that's incident on the reflector shown in following equations:

$$
\begin{gathered}
C R_{g}=\frac{A_{c}}{A_{r}} \\
C R_{o}=C R_{g} \times \eta_{o}
\end{gathered}
$$

where $C R_{g}$ is the geometrical concentration ratio, $A_{c}$ is the area of the concentrator, $A_{r}$ is the area of the receiver, $C R_{o}$ is the optical concentration ratio, and $\eta_{o}$ is the optical efficiency.

\subsection{Theoretical Model}

In this work, an in house developed and comprehensive 2D finite element based model [1] is used. The model includes three two-way coupled sub models to account for the thermal, optical, and electrical phenomena. The electrical sub model calculates the electrical output of the PV cells in terms of I-V curves and PV, while the detailed thermal and optical sub models have been presented elsewhere $[1,5]$ The thermal phenomena equation is presented here for completeness:

$$
\mathbf{M} \dot{T}+\mathbf{K} T-\boldsymbol{q}+(\mathbf{H}+\mathbf{R}) T=0
$$

where mass matrix is represented by $\mathbf{M}$ and accounts for the densities and heat capacities of all solid, liquid and melt phases. The temperature field is represented by $\dot{T}, \mathbf{K}$ is the conductivity matrix while $\mathbf{H}$ and $\mathbf{R}$ represent convection and radiative transfer. The irradiance matrix $q$ accounts mainly for shortwave radiative energy transfer into both systems that also converts to electrical energy.

The latent heat effect must be considered in a phase change process. This can be attained by incorporating temperature-dependent specific heat into enthalpy-based formulation [24] which can further be achieved by the effective heat capacity method [25]. The formulation for the effective heat capacity $\left(c_{p, e}\right)$ method is given in Equation (4) [26] which is used in the current work to introduce heat capacity during phase change process:

$$
c_{p, e}=c_{o}+\frac{H}{T_{2}-T_{1}} \quad T_{2} \leq T \leq T_{2} \quad c_{p, e}=c_{o}
$$

' $T_{1}$ ' is the onset melting or end set solidification temperature whereas ' $T_{2}$ ' is the end set melting or onset solidification temperature. The effective heat capacities of the selected phase change materials are obtained using Equation (4), and are shown in Figure 3. 
A five parameters model has been selected for the electrical output evaluation. These are the photocurrent $I_{p v}$, the reverse saturation diode current $I_{0}$, the shunt and series resistances $R_{p}$ and $R_{s}$, and finally the diode ideality or quality factor $a$. The main equation of the model relates that photocurrent and voltage, and is:

$$
I=I_{p v}-I_{0}\left[\exp \left(\frac{V+R_{S} I}{V_{t} a}\right)\right]-\frac{V+R_{S} I}{R_{p}}
$$

where $V_{t}=N_{s} k T / q$ is the thermal voltage of the array, in literature, a number of algorithms has been proposed for the estimation of the five parameters.

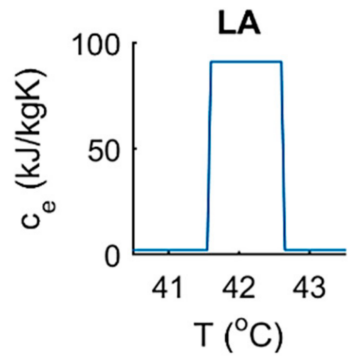

STL47
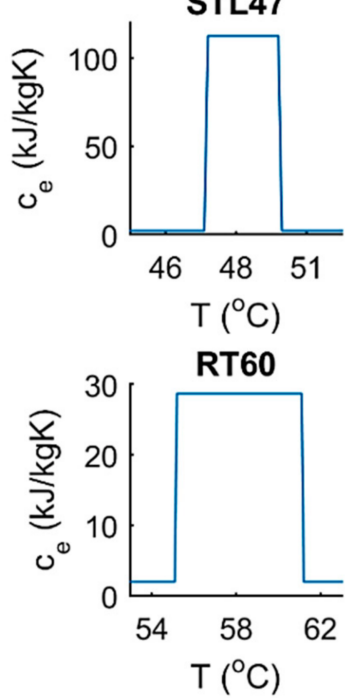

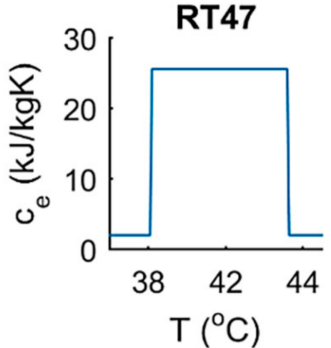

C48

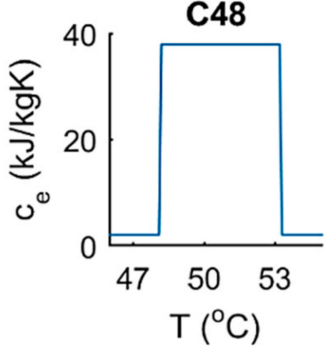

RT62

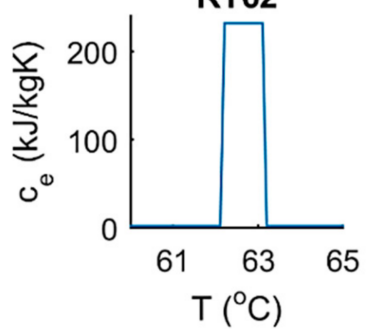

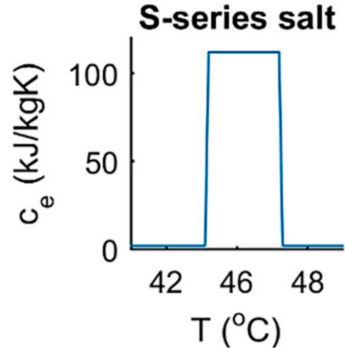

RT54

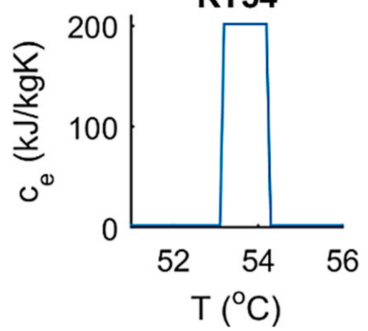

RT64

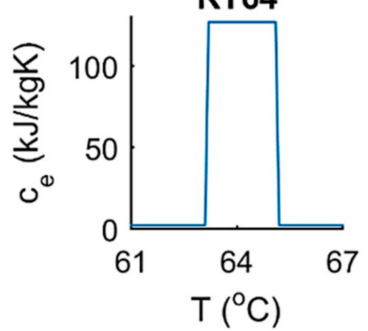

Figure 3. Effective heat capacities of selected phase change materials during phase transformation.

Here the algorithm by Villalva et al. [27] has been adapted and modified in order to couple the electrical sub model logic with the optical-thermal sub model and to estimate the five parameters. The proposed logic and new algorithm are shown in Figure 4. One of the core assumptions of the algorithm is that there is only one pair of values of $R_{s}$ and $R_{p}$ for which the maximum experimental power $P_{\max , e}$ is equal to the maximum power calculated by the model $P_{\max , m}$. To find the value of this pair $R_{s}$ and $R_{p}$, we use an iterative method until the condition $P_{\max , m}-P_{\max , e}<\varepsilon_{t o l}$ is met $\left(\varepsilon_{t o l}\right.$ is arbitrarily set at 0.0001$)$. The original model can successfully provide I-V curves only at nominal conditions $\left(25^{\circ} \mathrm{C}\right.$ and $1000 \mathrm{~W} / \mathrm{m}^{2}$ ). For use at other temperatures and irradiance levels, we calculate corrections to $I_{p v}$ and $I_{o}$, on the additional assumption that $I_{p v}$ is a linear function of irradiance, and $I_{o}$ is a function of temperature while $R_{p}$ and $a$ are maintained constant. Following this, first, we obtain the short circuit current $I_{s c}$ as a function of temperature and irradiance, and second, we obtain the open circuit voltage $V_{o c}$ as a function of temperature using Equation (3) and the electrical parameters shown in Table 2.

$$
I_{s c}=\left(I_{s c, n}+K_{I} \Delta T\right) \frac{q}{G_{n}} V_{o c}=\left(V_{o c, n}+K_{V} \Delta T\right)
$$


where $\Delta \mathbf{T}$ is the temperature difference (from the nominal temperature), $\mathbf{G}_{n}$ is the irradiance, while subscript $n$ denotes the nominal values. The photocurrent $I_{p v}$ is corrected in step II of the algorithm (Figure 4) by using the new value of $I_{s c}$ instead of $I_{s c, n}$. Then, $I_{0}$ is corrected by using the new $V_{o c}$ and $I_{p v}$ values. It is known experimentally that the series resistance $R_{S}$ decreases with the increase of irradiance [28], therefore, the $R_{S}$ is updated using expression $R_{s}=R_{s, n} G_{n} / G$ [29]. To obtain the corrected I-V curves, for the actual temperature and irradiance we use the Newton-Raphson method. The coupling of the thermal and optical sub models has already been completed earlier. The two sub models are coupled with the electrical sub model by the following equations for the calculation of the radiance converted to heat, $q$. after, and with the $q$, which are presented in Equation (7):

$$
q_{a o l}=(1-\rho-\alpha) q_{i} q_{e}=\left[\eta_{e i-S T C}+\mu\left(T-T_{a}\right)\right] q_{a o l} q=q_{a o l}-q_{e}
$$

where $q_{a o l}$ is the irradiance after the optical losses, $q_{e}$ is the irradiance used for electrical conversion, $\eta_{e i-S T C}$ is the manufacturer's provided electrical efficiency at standard test conditions, and $\mu$ is the power output temperature coefficient of the PV cell under standard test conditions.

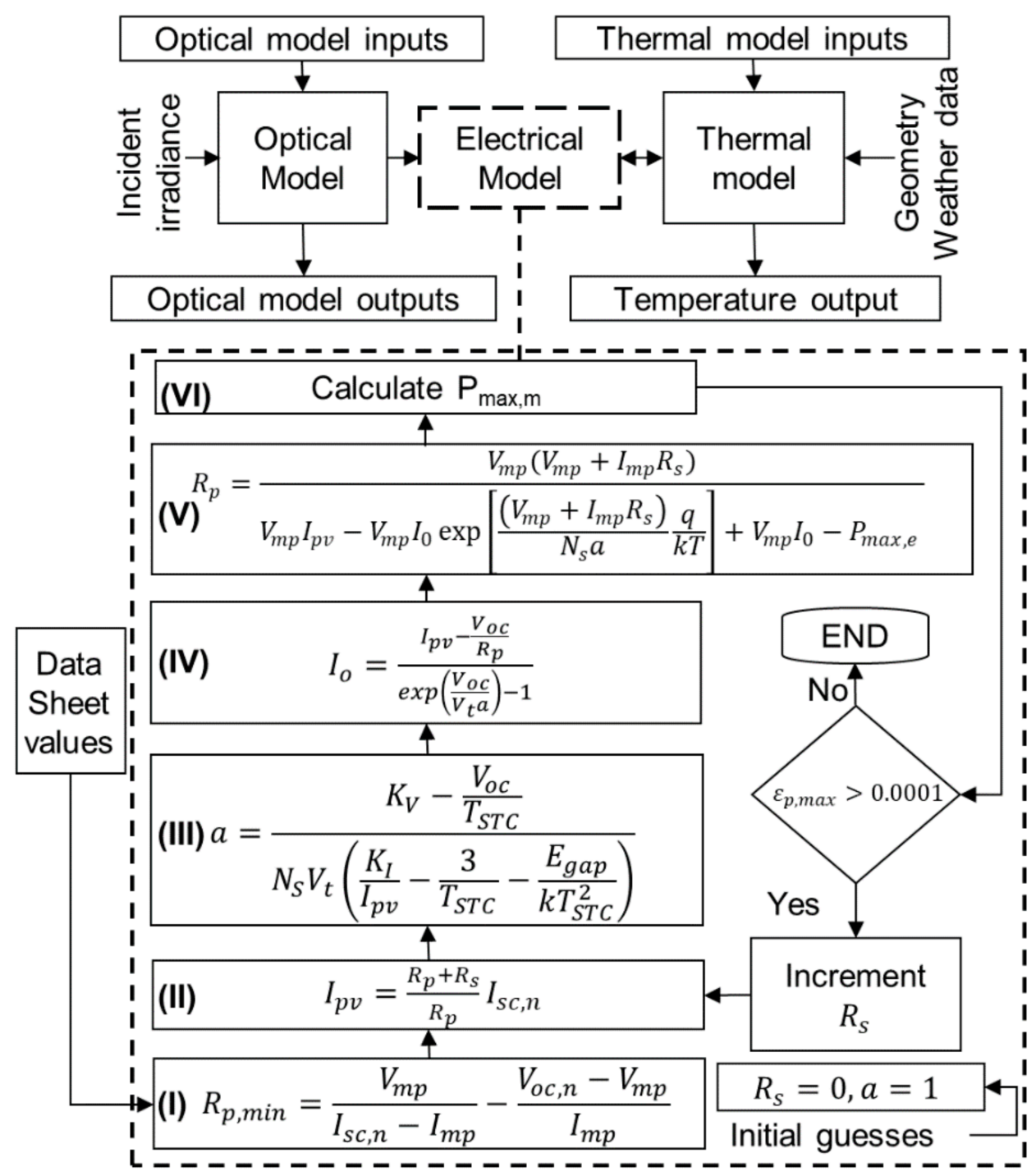

Figure 4. Flowchart of the fully coupled optical-thermal-electrical simulation model, with details of the electrical model. 
Table 2. Electrical parameters of the PV [19].

\begin{tabular}{cccc}
\hline \multicolumn{4}{c}{ Electrical Properties of PV Cell at STC } \\
\hline $\boldsymbol{I}_{\boldsymbol{s c}}(\boldsymbol{A})$ & $\boldsymbol{V}_{\boldsymbol{o c}}(\boldsymbol{V})$ & $\boldsymbol{I}_{\boldsymbol{m p}}(\boldsymbol{A})$ & $\boldsymbol{V}_{\boldsymbol{m p}}(\boldsymbol{V})$ \\
\hline 8.21 & 32.9 & 7.61 & 26.3 \\
\hline
\end{tabular}

\section{Numerical Procedure}

In the selected finite element method, an 8-node serendipity element (shape function) is used to achieve transformation from physical coordinates to natural coordinates. The mass, conductivity, convection, and irradiance matrices are assembled using direct addition of components method. The temporal discretization is carried out using the Crank-Nicholson method, and the system is solved at each time step. The convection, radiation, and electrical conversion of incident radiance are updated at every time step. The grid and time step have been selected after carrying out the grid-time independence studies to achieve relatively low computational-time without sacrificing system accuracy. It is found that a time step of $300 \mathrm{~s}$ and a grid of 24,600 elements with 75,081 nodes are adequate for this study.

Melting and solidification of the PCM are analyzed by relating the nodal (element) temperature with the phase transformation temperatures using a parameter called melt fraction, $M_{f}$ and calculated using Equation (8) while the energy stored, $Q_{s}$, in the PCM (as sensible and latent) is calculated using Equation (9) [30]. $m, C_{s}, C_{l}$ and $C_{e}$ are mass of PCM, heat capacity in solid state, heat capacity in liquid state and effective heat capacity of PCM, respectively:

$$
\begin{aligned}
& M_{f}=\left\{\begin{array}{cc}
0 & T<T_{1} \\
\frac{1}{T_{2}-T_{1}}\left(T-T_{1}\right) & T_{1} \leq T \leq T_{2} \\
1 & T>T_{2}
\end{array}\right. \\
& Q_{s}=\left\{\begin{array}{cc}
m c_{s}\left(T-T_{1}\right) & T<T_{1} \\
m c_{s}\left(T_{1}-T\right)+m c_{e}\left(T-T_{1}\right) & T_{1} \leq T \leq T_{2} \\
m c_{s}\left(T_{1}-T\right)+m c_{e}\left(T-T_{1}\right)+m c_{l}\left(T-T_{2}\right) & T>T_{2}
\end{array}\right.
\end{aligned}
$$

The melt fraction is a linear function of temperature $T$ (subscripts 1 and 2 denote melting onset and melting completion respectively) and takes values between 0 and 1 when PCM is in solid phase and liquid phase respectively. The thermal efficiency $\eta_{t h}$, which is the ratio of total stored energy $Q_{s}$ in the PCM to the total incident energy $q$ on area $A$, is calculated using Equation (10):

$$
\begin{gathered}
\eta_{t h}=\frac{\sum Q_{s}}{\int q(t) A \partial t} \\
\eta_{\text {overall }}=\eta_{t h}+\eta_{e l}
\end{gathered}
$$

Both, thermal and overall conversion efficiencies are used to determine and compare the effectiveness of the selected PCM in the CPVPCM system.

\section{Electrical and Thermal Output Validation}

A commercially available KC200GT high-efficiency multi-crystalline PV panel, manufactured by Kyocera [19] is selected to validate the electrical output of the developed model. The specifications of the module can be found elsewhere [19]. The electrical output of the module is simulated (i) for five irradiance levels, at a fixed cell temperature of $25^{\circ} \mathrm{C}$ (ii) three different cell temperatures at fixed irradiance of $1000 \mathrm{Wm}^{-2}$. The comparison between simulated I-V curves using the developed model and the manufacturer's provided data [19] is shown in Figure 5. There is a good agreement between simulated results, and experimental data is found with a maximum deviation of $\pm 6 \%$. The maximum power under nominal operating cell temperature and standard test conditions has been calculated 
with a deviation of $8-12 \%$, which is within the reported experimental uncertainty of $15 \%$ $(+10 \%$ and $-5 \%)$ by the manufacturer [19].

(a)

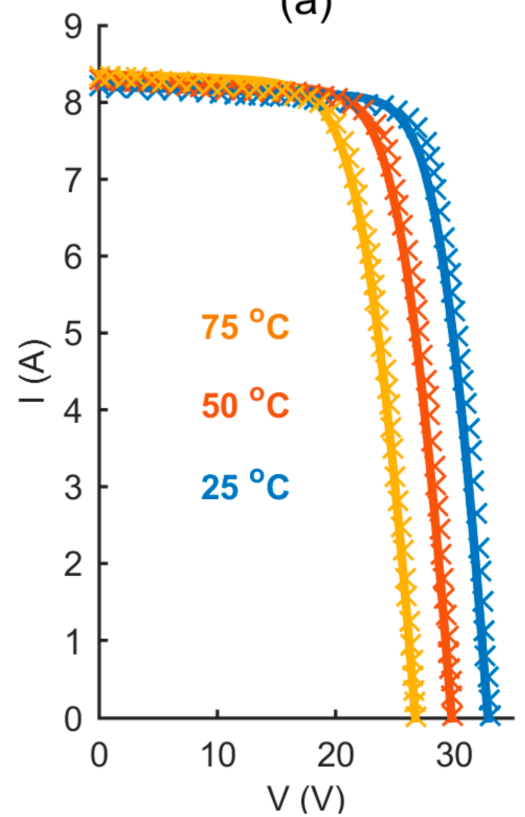

(b)

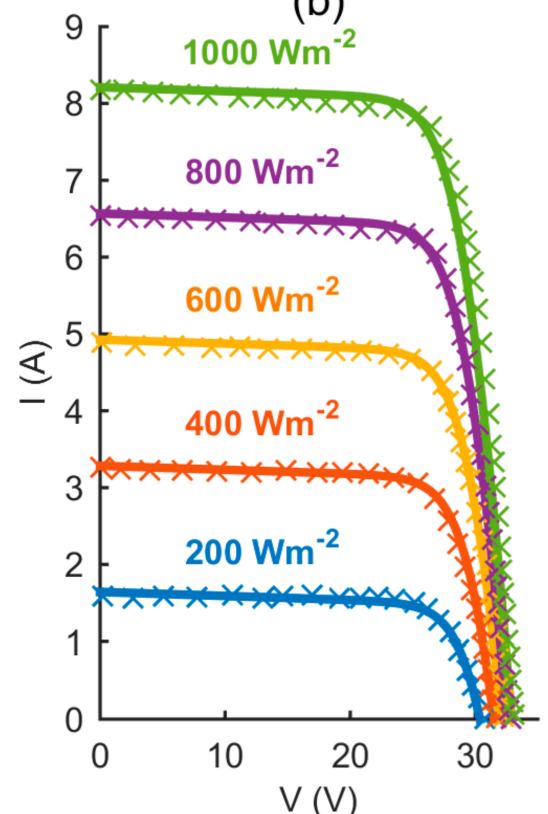

Figure 5. Validation of electrical output of the numerical model (I-V curves) where solid lines represent numerical results while $\times$ represents experimental results (a) different temperature $(\mathbf{b})$ different irradiances.

The temperature output of the PV and PVPCM systems reported in the literature [5] is used to compare the temperature output of the developed model. Both systems are simulated using the earlier described model, geometrical configuration, and material properties [5]. The cell temperature comparison is shown in Figure 6a for the PVPCM system and in (b) for the PV system. There is a good agreement between experimental and simulated results with an average standard deviation of less than $\pm 3 \%$; comparable to the reported cumulative experimental uncertainty of $5.26 \%$.

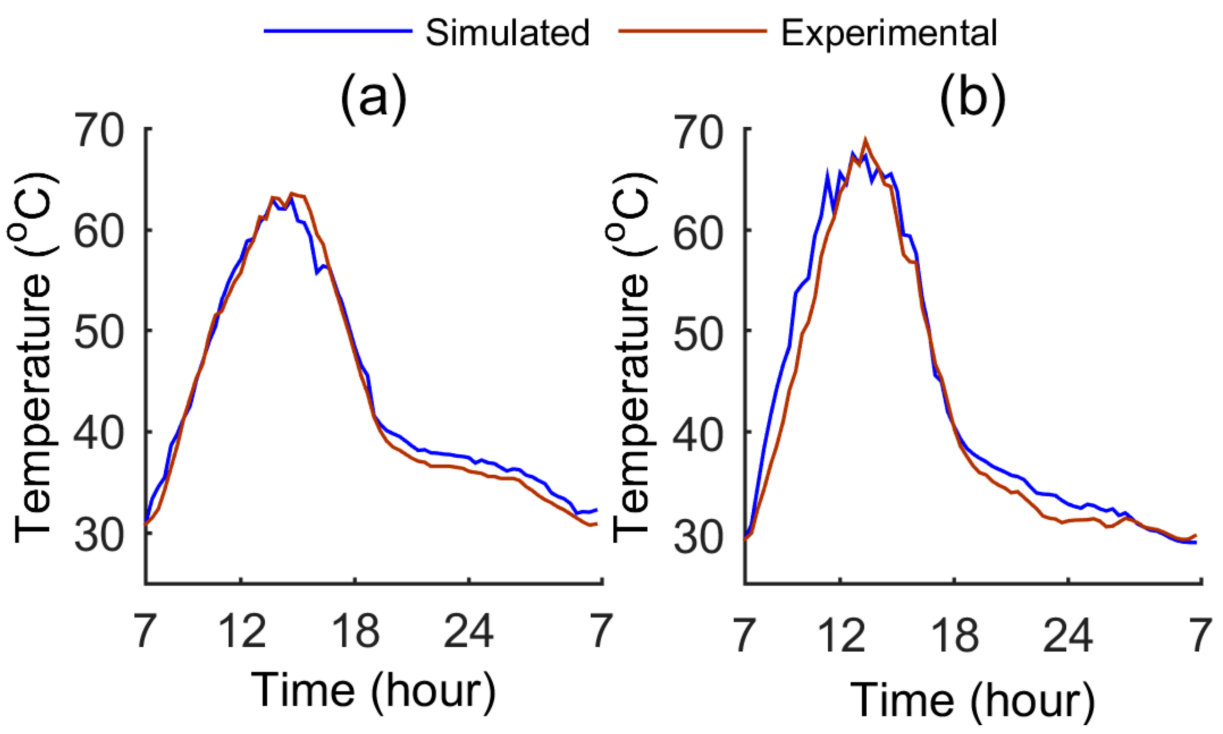

Figure 6. Validation of thermal output of the numerical model. 


\section{Results and Discussion}

\subsection{Optical Analysis of the Non-Ideal Solar Concentrator}

For the optical analysis of the non-ideal solar parabolic concentrator is assumed whose design methodology is presented elsewhere by authors [23]. A commercial software (TracePro, Lambda Research Corporation, Littleton, MA 01460, USA) is used in current work to analyze the optical behavior of the system. The CAD model for non-ideal parabolic concentrator (shown in Figure 7) is imported into TracePro to carry out ray tracing of the concentrator. The PV cell is assumed as a perfect absorber while the non-ideal reflector is assumed as a perfect mirror.
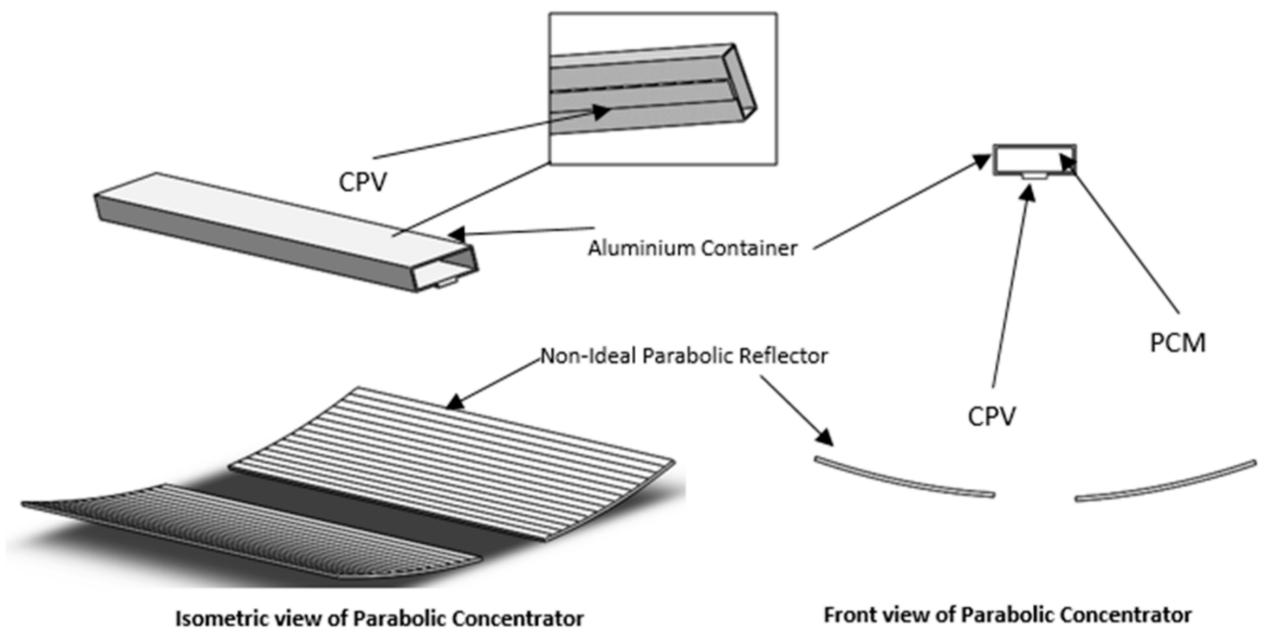

Isometric view of Parabolic Concentrato

Figure 7. CAD model of non-ideal parabolic concentrator.

After applying the properties to the receiver and the reflector, a rectangular shape source is produced, as shown in Figure 8. The properties applied to the source include irradiance type emission, the angular distance for the source is considered normal to surface. And for the Monte Carlo ray-tracing technique, 1 million rays are applied for the $1000 \mathrm{~W} / \mathrm{m}^{2}$. Figure 8 (right side) shows the total absorbed flux map and its profile distribution along with the receiver. The maximum flux achieved on the receiver is obtained to be $20,000 \mathrm{~W} / \mathrm{m}^{2}$.

\subsection{Melt Fraction}

Melt fractions of the selected PCM are analyzed, and results are shown in Figures 9-11. It is found that only LA and RT47 melt completely during each selected day of the year (melt fraction of 1) as shown in Figure 9 and achieve their maximum thermal energy storage potential. The S-series salt (referred to simply as salt in the subsequent text) and STL47 achieve melting and solidification during each month of the year except during December as shown in Figure 10. The other selected PCMs such as $\mathrm{ClimSel}^{\mathrm{TM}} \mathrm{C} 48$, RT54, RT60, RT62, and RT64 do not achieve complete melting during the winter months. The melt fraction for the months of December and February are shown in Figure 11. This behavior is due to their high phase transformation temperature ranges $\left(49-65^{\circ} \mathrm{C}\right)$ as shown in Table 1 . Based on melting/solidification behavior, it can be concluded that a PCM having a phase transformation temperature in the range of $41^{\circ} \mathrm{C}$ to $49^{\circ} \mathrm{C}$ (LA, RT47, Salt, and STL47) is suitable for application in the current CPVPCM configuration. 

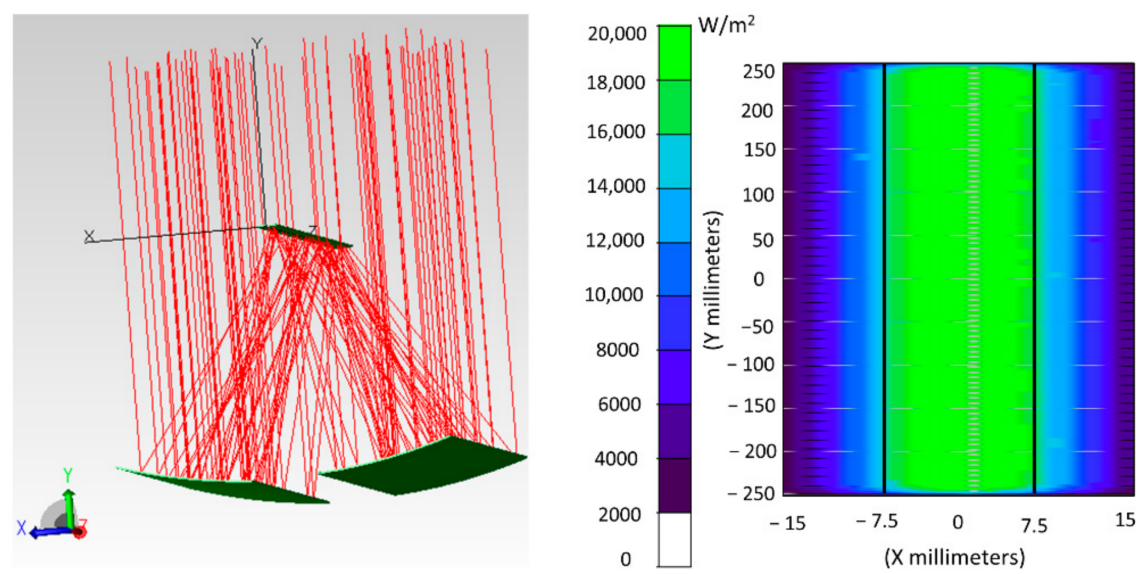

Figure 8. Optical model of the non-ideal parabolic concentrator with trace race (left side) and Irradiance map for the non-ideal parabolic trough with absorbed flux (right side).
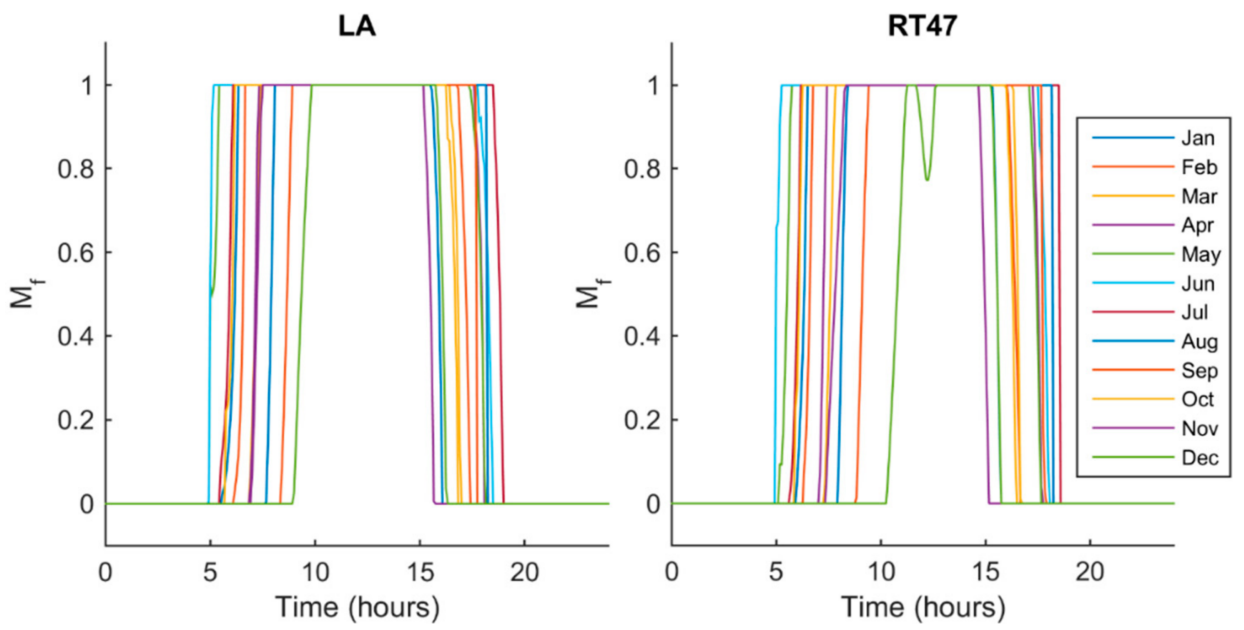

Figure 9. Melt fraction of LA and RT47 for all months of a year.
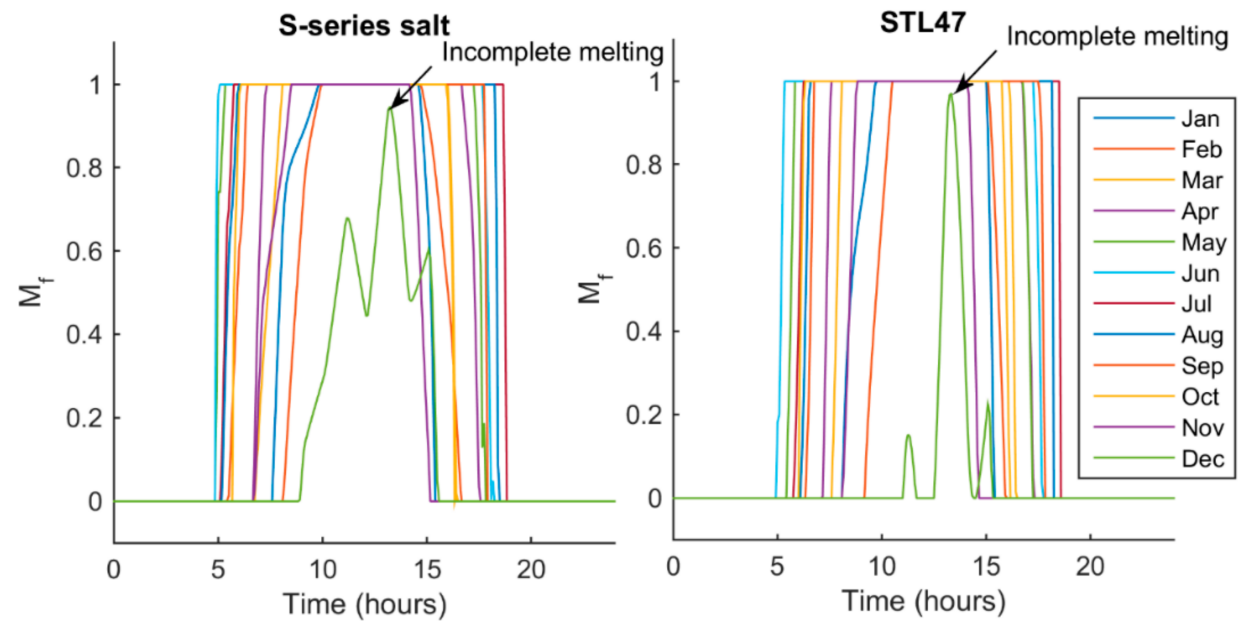

Figure 10. Melt fraction of S-series salt and STL47 for all months of a year. 

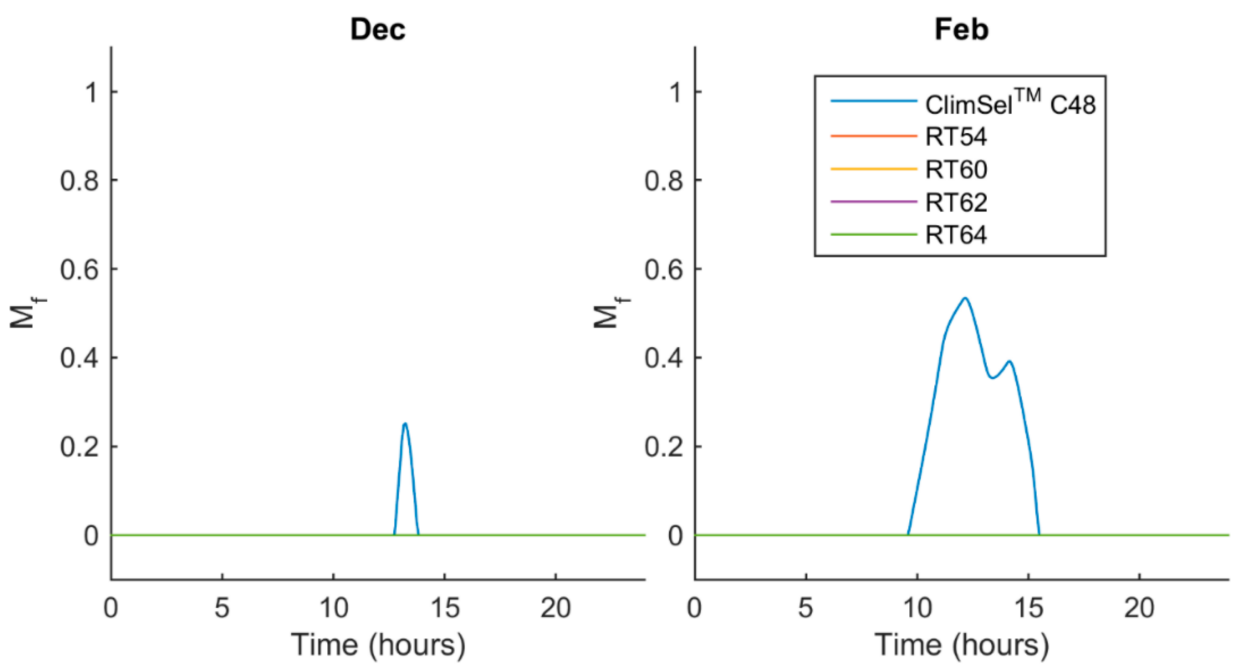

Figure 11. Melt fraction of $\mathrm{ClimSel}^{\mathrm{TM}}$ C48, RT54, RT60, RT62, and RT64 for the month of December and February.

\subsection{Thermal and Overall Efficiency}

The thermal efficiency of all selected PCMs in the CPVPCM system is calculated using Equation (10), and the result is shown in Figure 12. The analysis of the results has shown that the thermal efficiencies of salt and STL47 are better than all other PCM except in December which is due to their high latent heat of fusion. The PCM such as RT54, RT60, RT62, and RT64 has shown lower thermal efficiencies as compared to LA, RT47, salt, and STL47 due to their high phase transformation temperature. The thermal efficiency of RT47 is highest in February while LA has shown highest thermal efficiency in December. The analysis of thermal efficiency has shown that salt and STL47 are better from March until October while LA or RT47 are better in other months.

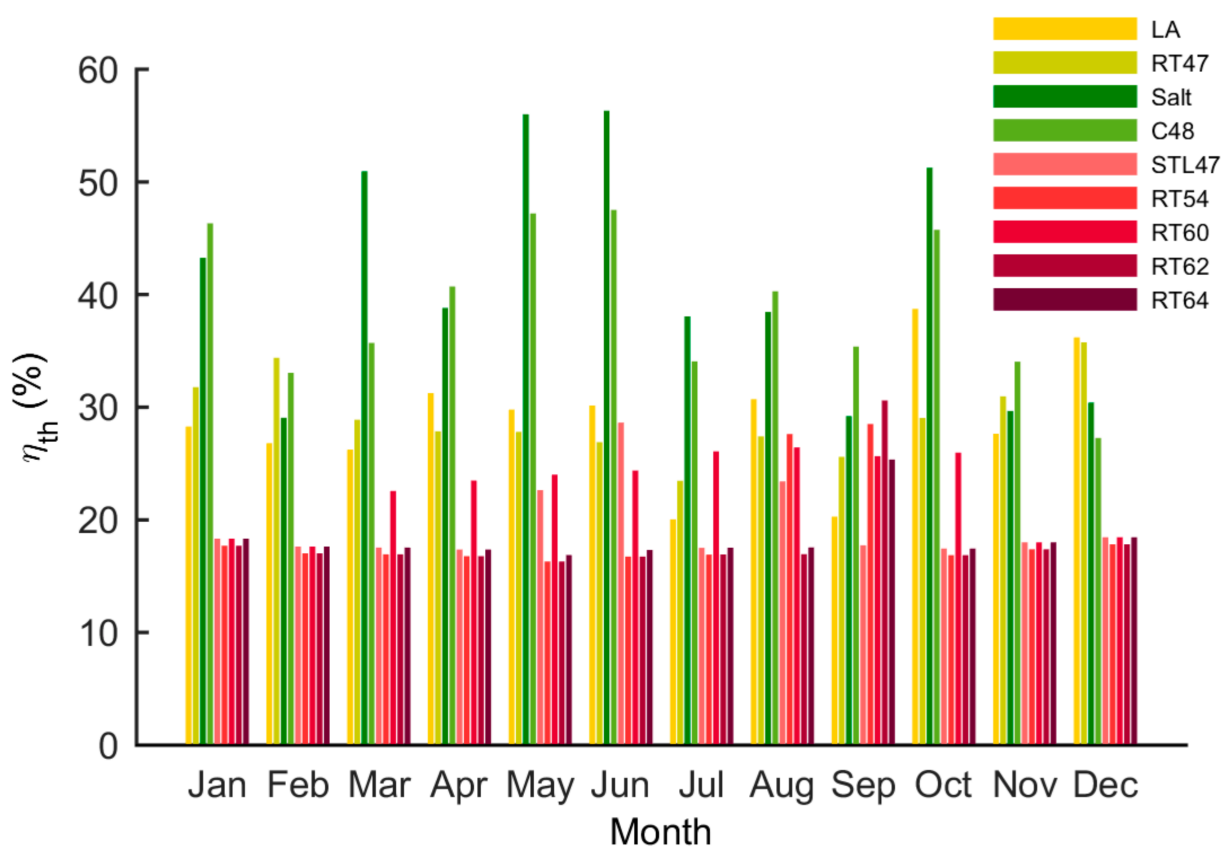

Figure 12. Comparison of the thermal efficiency of a CPVPCM system.

To establish a candidate PCM that can be used over a whole year, the overall efficiency is calculated using Equation (11) and shown in Figure 13. The overall efficiency has shown that salt and STL47 perform better than all other PCMs. The overall efficiencies of salt and STL47 are found to be $54.4 \%$ and $52.2 \%$, respectively. 


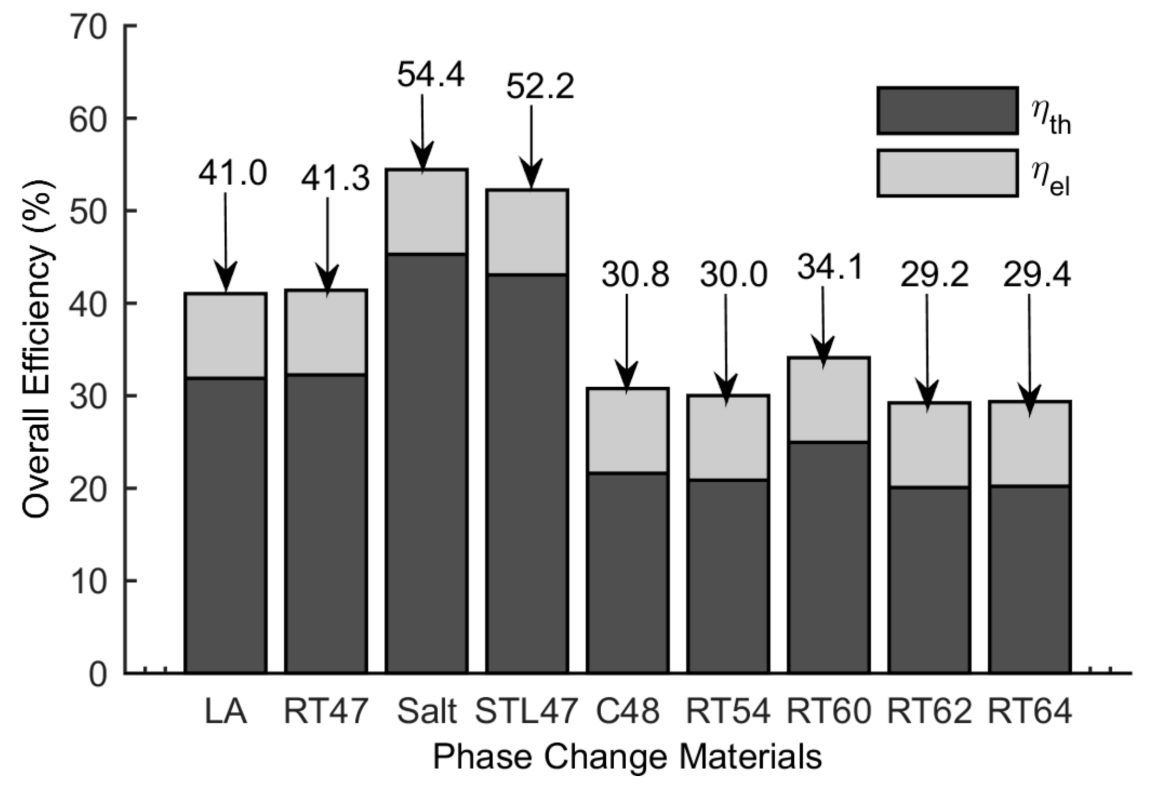

Figure 13. The overall efficiencies of a CPVPCM system.

Although, salt and STL47 do not completely melt in December they do perform well in all other months. In the authors' view, they perform better due to their high latent heat of fusion and high mass for energy storage. Based on the results, it is found that the salt is better than all other PCM in the current configuration of the CPVPCM system. In the subsequent sections, the comparison of CPVPCM having salt as a PCM and PV system is presented.

\subsection{Temperature}

The comparison of transient temperatures of CPVPCM (PCM refers to the salt in subsequent text, unless otherwise specified) and PV system for March, July and November are presented in Figure 14 while average and peak temperatures over the year for both systems are presented in Figure 15.

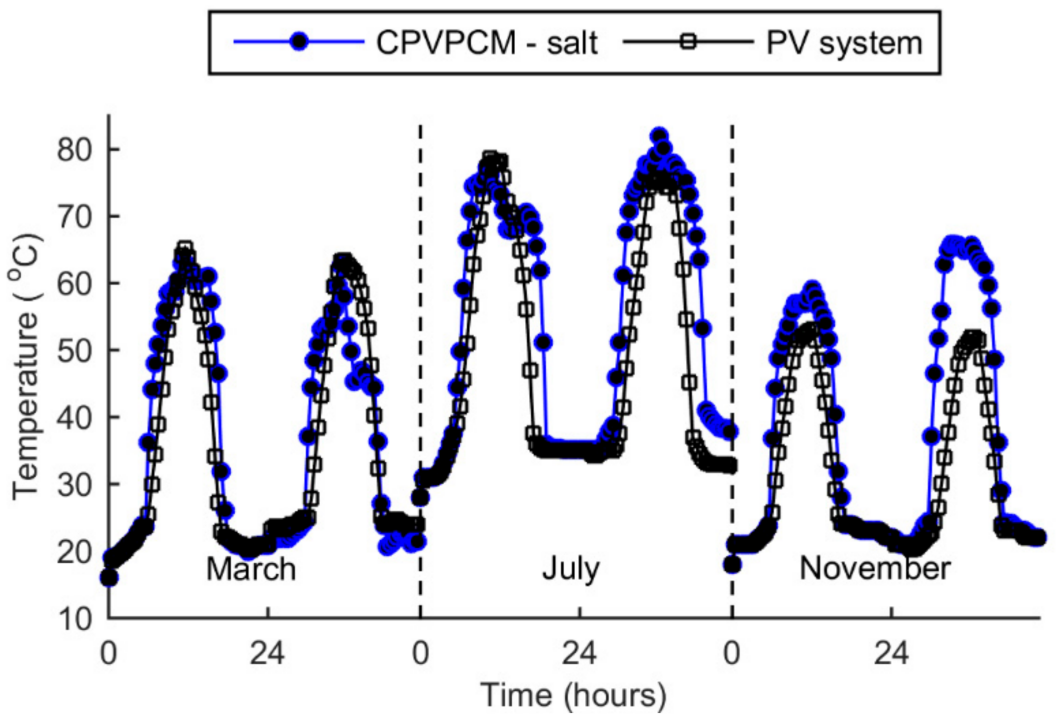

Figure 14. Comparison of temperatures of CPVPCM and PV systems. 


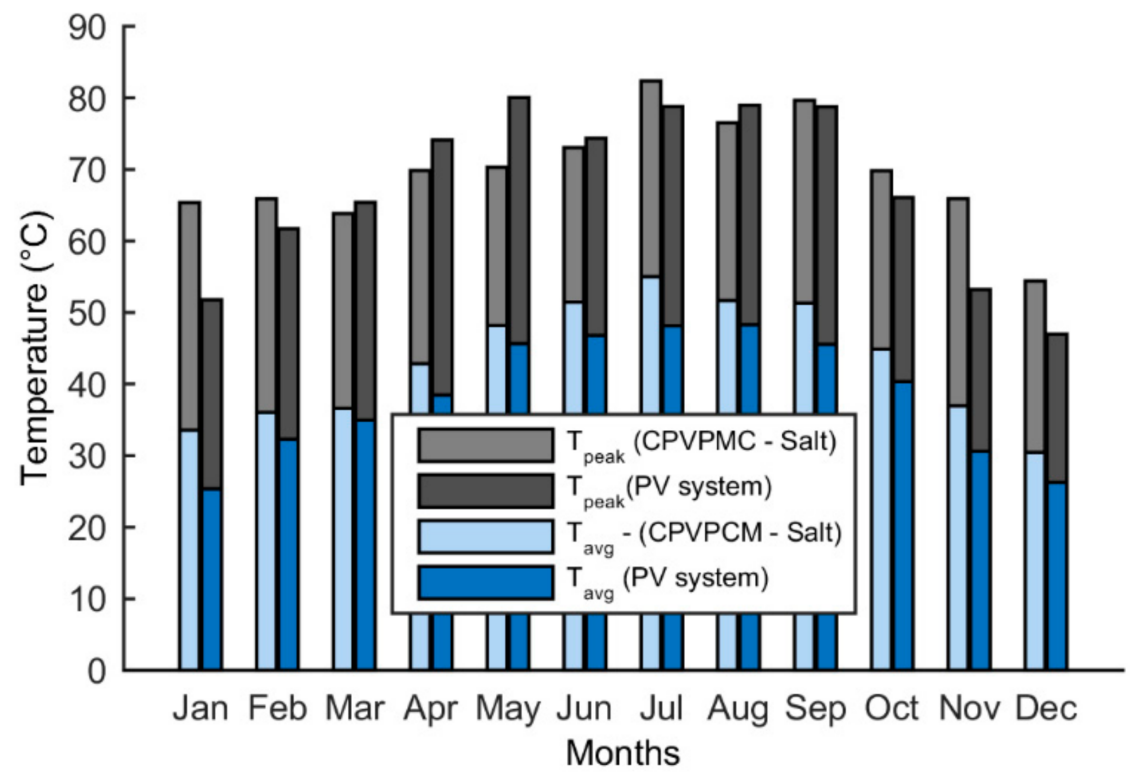

Figure 15. Comparison of peak and average temperature of both systems.

It is found that the peak temperature of the CPVPCM system stays below the limiting temperature of $85^{\circ} \mathrm{C}$ [19] during all months with the maximum of $82.1^{\circ} \mathrm{C}$ in July. It is also found that the temperatures between the CPVPCM system and PV system vary in the range of $1.8 \%$ to $20.8 \%$.

\subsection{Electrical Output}

Further studies are carried out to investigate and compare the peak and average power produced by the CPVPCM and PV systems for an equal footprint of $1 \mathrm{~m}^{2}$ and the result is presented in Figure 16. It is found that the CPVPCM system consistently produces higher peak power and average power. The maximum difference between peak powers produced by CPVPCM and PV systems is found to be $~ 31 \%$ in December while the minimum difference of $\sim 6.1 \%$ is found in June. It is worth noting here that the CPVPCM system produces higher peak power as it is exposed to higher irradiance level due to tracking. Furthermore, it has produced higher peak power in the winter and autumn months due to the lower PV cell temperature as compared to the summer months (refer to Figure 16).

Further investigations are carried out to find power produced over a day for both systems and the result is shown in Figure 17. The CPVPCM system consistently produces more power over a day as compared to the $\mathrm{PV}$ system. The maximum power of $0.94 \mathrm{kWh}$ per day is produced by the CPVPCM system while the PV system produces a maximum power of $0.61 \mathrm{kWh}$ per day. The CPVPCM system produces an average power of $0.84 \mathrm{kWh}$ per day while the corresponding average power produced by the PV system is found to be $0.50 \mathrm{kWh}$ per day. The analysis of the result has also shown that the CPVPCM system produces $40 \%$ more power than the PV system, which makes it suitable to achieve higher electrical output for an equal footprint of $1 \mathrm{~m}^{2}$. 


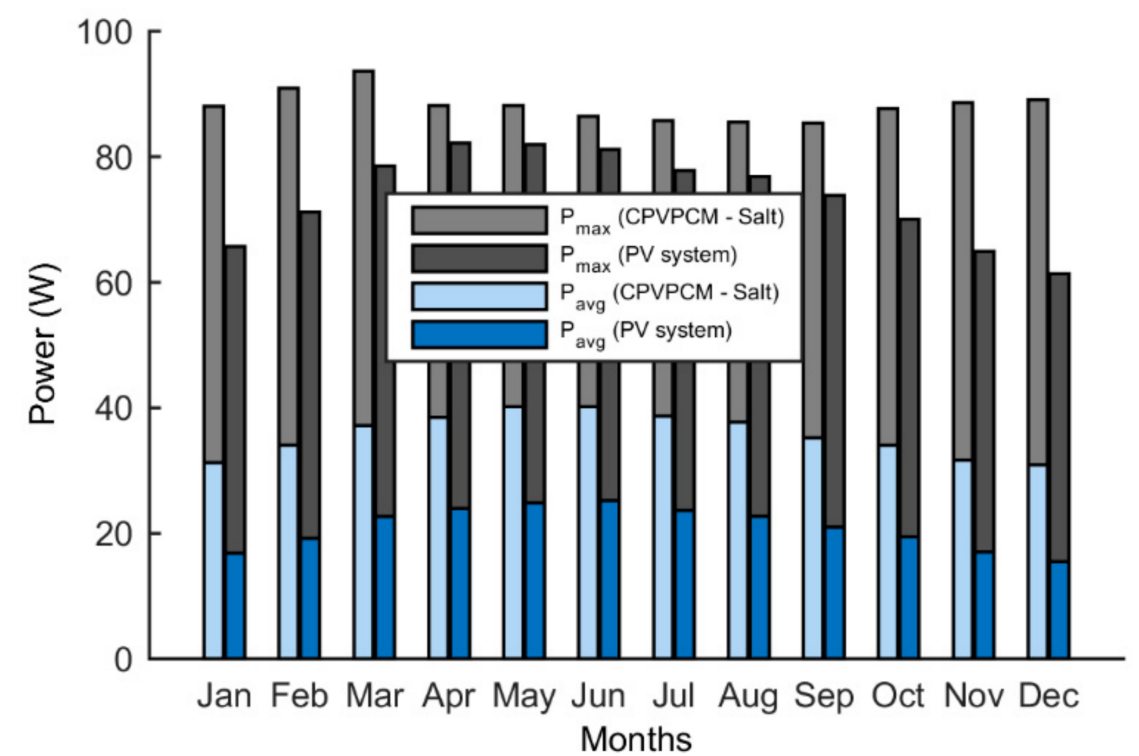

Figure 16. Comparison of maximum and average power of CPVPCM system with salt and PV system.

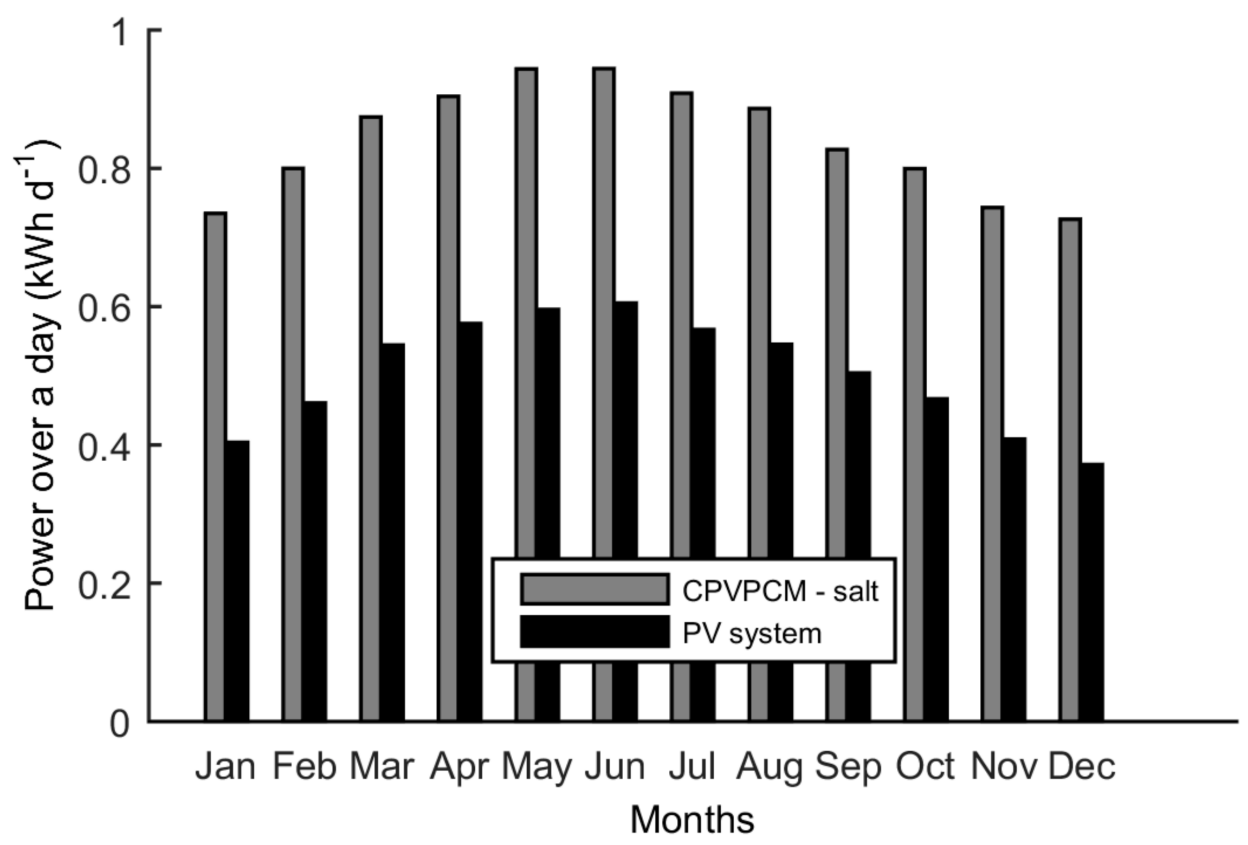

Figure 17. Comparison of power generated over a day for a CPVPCM system with salt and PV system.

\section{Conclusions}

In this work, a comprehensive 2D finite element-based heat transfer fully coupled thermal-optical-electrical model is used to predict and compare the electrical and thermal output of a CPVPCM system and a PV system. The outputs of the both systems are compared, and the following conclusions are made:

(1) A PCM having a phase transformation temperature in the range of $41{ }^{\circ} \mathrm{C}$ to $49{ }^{\circ} \mathrm{C}$ are suitable in the current configuration.

(2) The highest overall efficiency of 54.4\% is found for the CPVPCM system with salt, therefore, thus is considered the best PCM in the current configuration.

(3) The peak temperature of the CPVPCM system with salt stays below the limiting temperature of $85^{\circ} \mathrm{C}$. The maximum temperature of the PV cell in the CPVPCM system is found as $82.1^{\circ} \mathrm{C}$ in July. 
(4) The CPVPCM system with salt consistently produces more power over a day as compared to the PV system.

The analysis of the electrical and thermal output of both systems has shown that the CPVPCM system performs better than the PV system for an equal footprint of $1 \mathrm{~m}^{2}$. However, the assumption of tracking for the CPVPCM system may have skewed the electrical output result in its favor due to a collection of higher incident irradiance. Further studies are required by including electricity production cost as an added evaluation criterion along with using experimentally measured irradiances to quantify and compare the benefits of both CPVPCM and PV systems.

Author Contributions: Conceptualization, J.S. and K.E.K., methodology, A.G., J.S., K.E.K., A.H., and M.R.S.; software, J.S., A.H., and F.A.; validation, J.S., A.G., K.E.K., M.R.S., A.H. and F.A.; formal analysis, A.G., J.S.; investigation, J.S., A.G., K.E.K.; resources, K.E.K., and J.S.; data curation, J.S. and A.G.; writing —original draft preparation, J.S. and A.H.; writing—review and editing, J.S., A.G., K.E.K., and A.H.; visualization, J.S.; supervision, K.E.K.; project administration, K.E.K.; funding acquisition, J.S., K.E.K. All authors have read and agreed to the published version of the manuscript.

Funding: This publication was made possible by a PDRA award [PDRA2-1105-14044] from the Qatar National Research Fund (a member of The Qatar Foundation). The statements made herein are solely the responsibility of the authors.

Institutional Review Board Statement: Not applicable.

Informed Consent Statement: Not applicable.

Acknowledgments: The HPC resources and services used in this work were provided by the IT Research Computing group in Texas A\&M University at Qatar. IT Research Computing is funded by the Qatar Foundation for Education, Science and Community Development (http:/ /www.qf.org.qa, accessed on 1 February 2021). The authors would also like to acknowledge the department of mechanical engineering, University of Engineering \& Technology, Lahore and University of Exeter for their invaluable support in conducting this research work.

Conflicts of Interest: The authors declare no conflict of interest. The funders had no role in the design of the study; in the collection, analyses, or interpretation of data; in the writing of the manuscript, or in the decision to publish the results.

\section{References}

1. Sarwar, J.; Abbas, A.E.; Kakosimos, K.E. Effect of the thermophysical properties of a phase change material on the electrical output of a concentrated photovoltaic system. In Proceedings of the 2017 IEEE 44th Photovoltaic Specialist Conference (PVSC), Washington, DC, USA, 25-30 June 2017.

2. Ceylan, İ.; Gürel, A.E.; Ergün, A.; Tabak, A. Performance analysis of a concentrated photovoltaic and thermal system. Sol. Energy 2016, 129, 217-223. [CrossRef]

3. Radziemska, E. The effect of temperature on the power drop in crystalline silicon solar cells. Renew. Energy 2003, 28, 1-12. [CrossRef]

4. Maleki, A.; Haghighi, A.; Assad, M.E.H.; Mahariq, I.; Nazari, M.A.J.S.E. A review on the approaches employed for cooling PV cells. Sol. Energy 2020, 209, 170-185. [CrossRef]

5. Hasan, A.; Sarwar, J.; Alnoman, H.; Abdelbaqi, S. Yearly energy performance of a photovoltaic-phase change material (PV-PCM) system in hot climate. Sol. Energy 2017, 146, 417-429. [CrossRef]

6. Browne, M.; Norton, B.; McCormack, S. Phase change materials for photovoltaic thermal management. Renew. Sustain. Energy Rev. 2015, 47, 762-782. [CrossRef]

7. Kibria, M.; Saidur, R.; Al-Sulaiman, F.; Aziz, M.M.A.J.S.E. Development of a thermal model for a hybrid photovoltaic module and phase change materials storage integrated in buildings. Sol. Energy 2016, 124, 114-123. [CrossRef]

8. Waqas, A.; Jie, J. Effectiveness of Phase Change Material (PCM) for cooling of PV panel for hot climate. J. Sol. Energy Eng. 2018, 140, 041006. [CrossRef]

9. Sharma, S.; Tahir, A.; Reddy, K.; Mallick, T.K. Performance enhancement of a Building-Integrated Concentrating Photovoltaic system using phase change material. Sol. Energy Mater. Sol. Cells 2016, 149, 29-39. [CrossRef]

10. Sarwar, J.; Hasnain, A.; Abbas, A.E.; Kakosimos, K.E.J.T.S. Comparative analysis of a novel low concentration dual photovoltaic/phase change material system with a non-concentrator photovoltaic system. Therm. Sci. 2019, 25, 468. [CrossRef] 
11. Emam, M.; Ahmed, M.; Ookawara, S. Performance Enhancement of Concentrated Photovoltaic System Using Phase-Change Material. In Proceedings of the ASME 2016 10th International Conference on Energy Sustainability Collocated with the ASME 2016 Power Conference and the ASME 2016 14th International Conference on Fuel Cell Science, Engineering and Technology, Charlotte, NC, USA, 26-30 June 2016; p. V001T08A006.

12. Baqi, S.A.; Hassan, A.; Shah, A.H. Performance Optimization of Concentrated Photovoltaic-Thermal (CPV-T) System Employing Phase Change Material (PCM) in Hot Climate. In Renewable Energy and Sustainable Buildings; Springer: Berlin/Heidelberg, Germany, 2020; pp. 579-594.

13. Cui, T.; Xuan, Y.; Li, Q. Design of a novel concentrating photovoltaic-thermoelectric system incorporated with phase change materials. Energy Convers. Manag. 2016, 112, 49-60. [CrossRef]

14. Hasnain, A.; Sarwar, J.; Abbas, Q.; Younas, M.A.; Kakosimos, K.E. Thermal and Electrical Performance Analysis of a Novel Medium Concentration Dual Photovoltaic System for Different Phase Change Materials. In Proceedings of the ASME 2020 International Mechanical Engineering Congress and Exposition, Online. 16-19 November 2020.

15. Karthick, A.; Ramanan, P.; Ghosh, A.; Stalin, B.; Kumar, R.V.; Baranilingesan, I. Performance enhancement of copper indium diselenide photovoltaic module using inorganic phase change material. Asia Pac. J. Chem. Eng. 2020, 15, e2480. [CrossRef]

16. Karthick, A.; Murugavel, K.K.; Ghosh, A.; Sudhakar, K.; Ramanan, P. Investigation of a binary eutectic mixture of phase change material for building integrated photovoltaic (BIPV) system. Sol. Energy Mater. Sol. Cells 2020, 207, 110360. [CrossRef]

17. Karthick, A.; Manokar Athikesavan, M.; Pasupathi, M.K.; Manoj Kumar, N.; Chopra, S.S.; Ghosh, A. Investigation of Inorganic Phase Change Material for a Semi-Transparent Photovoltaic (STPV) Module. Energies 2020, 13, 3582. [CrossRef]

18. Pasupathi, M.K.; Alagar, K.; Matheswaran, M.M.; Ghosh, A. Characterization of Hybrid-nano/Paraffin Organic Phase Change Material for Thermal Energy Storage Applications in Solar Thermal Systems. Energies 2020, 13, 5079. [CrossRef]

19. KC200GT, K. High Efficiency Multicrystal Photovoltaic Module. Available online: https://www.energymatters.com.au/images/ kyocera/KC200GT.pdf (accessed on 1 February 2021).

20. Bird, R.E.; Hulstrom, R.L. Simplified Clear Sky Model for Direct and Diffuse Insolation on Horizontal Surfaces; Solar Energy Research Inst.: Golden, CO, USA, 1981.

21. Hecht, E. Optics; Pearson: Harlow, UK, 2012.

22. Herrero, R.; Victoria, M.; Domínguez, C.; Askins, S.; Antón, I.; Sala, G. Understanding causes and effects of non-uniform light distributions on multi-junction solar cells: Procedures for estimating efficiency losses. AIP Conf. Proc. 2015, $1679,050006$.

23. Sarwar, J.; Lemarchand, P.; McCormack, S.; Huang, M.; Norton, B. Novel Method to Design Non-Ideal Parabolic Dish Concentrator for Concentrated Photovoltaic Application; Its Theoratical Analysis and Experimental Characterisation for Design Validation. In Proceedings of the 28th European Photovoltaic Solar Energy Conference and Exhibition, Paris, France, 30 September-4 October 2013.

24. Reddy, J.N.; Gartling, D.K. The Finite Element Method in Heat Transfer and Fluid Dynamics, 2nd ed.; CRC: Boca Raton, FL, USA, 2001; p. 469.

25. Runnels, S.R.; Carey, G.F. Finite element simulation of phase change using capacitance methods. Numer. Heat Transf. Part B Fundam. 1991, 19, 13-30. [CrossRef]

26. Lamberg, P.; Lehtiniemi, R.; Henell, A.-M. Numerical and experimental investigation of melting and freezing processes in phase change material storage. Int. J. Therm. Sci. 2004, 43, 277-287. [CrossRef]

27. Villalva, M.G.; Gazoli, J.R.; Filho, E.R. Comprehensive approach to modeling and simulation of photovoltaic arrays. IEEE Trans. Power Electron. 2009, 24, 1198-1208. [CrossRef]

28. Lal, M.; Singh, S. A new method of determination of series and shunt resistances of silicon solar cells. Sol. Energy Mater. Sol. Cells 2007, 91, 137-142.

29. Brano, V.L.; Orioli, A.; Ciulla, G.; Di Gangi, A. An improved five-parameter model for photovoltaic modules. Sol. Energy Mater. Sol. Cells 2010, 94, 1358-1370. [CrossRef]

30. Solomon, L.; Oztekin, A. Exergy analysis of cascaded encapsulated phase change material—High-temperature thermal energy storage systems. J. Energy Storage 2016, 8, 12-26. [CrossRef] 